\title{
A Pin1/PML/P53 axis activated by retinoic acid in NPM-1c acute myeloid leukemia
}

\author{
Rita Hleihel, ${ }^{1,2^{*}}$ Hiba El Hajj, ${ }^{3 *}$ Hsin-Chieh Wu, ${ }^{46^{*}}$ Caroline Berthier, ${ }^{46}$ Hong-Hu \\ Zhu, ${ }^{7}$ Radwan Massoud, ${ }^{1}$ Zaher Chakhachiro, ${ }^{8}$ Marwan El Sabban, ${ }^{2}$ Hugues de \\ The $^{46 \#}$ and Ali Bazarbachi, ${ }^{1,2 \#}$
}

${ }^{1}$ Department of Internal Medicine, American University of Beirut, Beirut, Lebanon; ${ }^{2}$ Department of Anatomy, Cell Biology and Physiological Sciences, American University of Beirut, Beirut, Lebanon; ${ }^{3}$ Department of Experimental Pathology, Immunology and Microbiology, Beirut, Lebanon; " Université de Paris, INSERM UMR 944, CNRS UMR 7212 , Haematologica 2021 Volume 106(12):3090-3099 Equipe labellisée par la Ligue Nationale Contre le Cancer, IRSL, Hôpital St. Louis, Paris, France; ${ }^{5}$ Oncologie Moléculaire, Hôpital St. Louis, Paris, France; ${ }^{6}$ Collège de France, PSL University, CIRB, INSERM UMR 1050, CNRS UMR 7241, Paris, France; 'Department of Hematology, The First Affiliated Hospital, College of Medicine, Zhejiang University, Hangzhou, People's Republic of China and ${ }^{8}$ Department of Pathology and Laboratory Medicine, American University of Beirut, Beirut, Lebanon

${ }^{\star} \mathrm{RH}, \mathrm{HEH}$ and $\mathrm{HCW}$ contributed equally as co-first authors.

${ }^{\#} H D T$ and $A B$ contributed equally as co-senior authors.

\section{ABSTRACT}

$\mathrm{R}$ etinoic acid (RA) was proposed to increase survival of chemotherapy-treated patients with nucleophosmin-1 (NPM-1c)-mutated acute myeloid leukemia. We reported that, ex vivo, RA triggers NPM-1c degradation, P53 activation and growth arrest. PML organizes domains that control senescence or proteolysis. Here, we demonstrate that PML is required to initiate RA-driven NPM-1c degradation, P53 activation and cell death. Mechanistically, RA enhances PML basal expression through inhibition of activated Pin1, prior to NPM-1c degradation. Such PML induction drives P53 activation, favoring blast response to chemotherapy or arsenic in vivo. This RA/PML/P53 cascade could mechanistically explain RA-facilitated chemotherapy response in patients with NPM-1c mutated acute myeloid leukemia.

\section{Correspondence:}

ALI BAZARBACHI

bazarbac@aub.edu.lb

Received: October 24, 2020.

Accepted: May 3, 2021.

Pre-published: May 27, 2021.

https://doi.org/10.3324/haematol.2020.274878

(C)2021 Ferrata Storti Foundation

Material published in Haematologica is covered by copyright. All rights are reserved to the Ferrata Storti Foundation. Use of published material is allowed under the following terms and conditions:

https://creativecommons.org/licenses/by-nc/4.0/legalcode. Copies of published material are allowed for personal or internal use. Sharing published material for non-commercial purposes is subject to the following conditions:

https://creativecommons.org/licenses/by-nc/4.0/legalcode, sect. 3. Reproducing and sharing published material for commercial purposes is not allowed without permission in writing from the publisher.

\section{Introduction}

Nucleophosmin 1 (NPM-1) is a chaperone implicated in multiple processes, notably ribosomal biogenesis and growth control. NPM-1 alterations have been directly implicated in cancer development, through a variety of mechanisms, including chromosomal translocations and recurrent mutations. ${ }^{1}$ In acute myeloid leukemia (AML), the most prevalent one is a short nucleotide insertion that induces a frame shift in the C-terminus of the protein, yielding NPM-1c. ${ }^{2} \mathrm{NPM}-1 \mathrm{c}$ has been demonstrated to have multiple properties, including inhibition of P53 and cytoplasmic sequestration of key regulatory proteins. ${ }^{3,4}$ AML with NPM-1 mutation is the most common subtype, accounting for more than one-third of AML. More than half of the patients ultimately relapse when treated with conventional chemotherapy. NPM-1associated cases of AML in relapsed or elderly patients unfit for chemotherapy represent a major unmet medical need.

Retinoic acid (RA) is a hormone with multiple effects on development and tissue homeostasis. RA has a dual effect on stem cell fate and differentiation following modulation of transcription. High doses of RA have also been shown to inhibit Pin1, a protein-modifying enzyme involved in the activation of multiple growth suppressive pathways. ${ }^{5,6} \mathrm{RA}$ demonstrated unambiguous clinical efficacy in a variety of conditions including neuroblastoma and acute promyelocytic leukemia (APL).? In APL, RA directly targets the driving PML/RARA oncoprotein for degradation and produces complete remissions ${ }^{8}$ through activation of a PML/P53 senescence checkpoint. ${ }^{9,10}$ In other AML, in vitro studies suggested some efficacy of RA. ${ }^{11,12}$ However, contradictory results emerged from clinical trials investigating the efficacy of RA in non-APL AML. ${ }^{13}$ Whereas an Austrian-German study (AML HD98B) found that the addition of RA to intensive chemotherapy improved remission, event-free survival, 
and overall survival, ${ }_{13}^{13}$ U United Kingdom Medical Research Council trial failed to demonstrate any overall advantage of adding RA to chemotherapy. ${ }^{14,15}$

Intriguingly, the potential benefit of RA co-administration with chemotherapy seems restricted to patients bearing an NPM-1c mutation in the absence of an fms-like tyrosine kinase 3 (FLT3)-internal tandem duplication (ITD). ${ }^{16}$ Whether this efficacy reflects RA-induced AML differentiation, as observed in several non-APL AML primary patients' cells or models ${ }^{11,12}$ remains to be elucidated. Interestingly, NPM-1c is degraded upon administration of RA, suggesting that loss of NPM-1c expression may underlie, or at least contribute to, RA-driven differentiation and apoptosis $e x$ vivo. ${ }^{17,18}$ Ex vivo, NPM-1c degradation was accelerated by coadministration of arsenic trioxide (ATO) which, like RA, may inhibit Pin1, a protein-modifying enzyme implicated in growth control through multiple mechanisms. ${ }^{5,6,19}$ The actual mechanism of RA-induced enhancement of the response to chemotherapy in NPM-1c- AML remains to be elucidated.

PML (TRIM19) nucleates nuclear bodies, which are stress-responsive domains that have growth suppressive properties. ${ }^{20}$ In vivo, PML nuclear bodies are oxidative stress sensors that control P53 activation. ${ }^{21}$ PML plays a key role in the therapeutic response of APL.,222.25 The expression of PML is altered in multiple tumor types, most often through PML protein loss upon activation of several degradation pathways, including Pin1. ${ }^{26.30}$ Interestingly, we previously reported impairment of PML nuclear body formation in NPM-1c-driven AML. ${ }^{17,18}$

Here, we unravel an unexpected role of PML in RA-initiated responses of NPM-1c AML cells. PML is required to initiate RA-driven NPM-1c degradation, P53 activation and cell death. Mechanistically, RA stabilizes PML through inhibition of overexpressed and activated Pin1, enforcing growth arrest. Such RA-induced activation of the PML/P53 signaling cascade enhances the activity of chemotherapy or arsenic in vivo. Our studies identify PML as an unsuspected actor downstream of RA in NPM-1c AML.

\section{Methods}

\section{Cell lines and treatments}

OCI-AML3 or OCI-AML2 AML cells (harboring the NPM-1c mutation without FLT3-ITD or wild type [wt] NPM-1 respectively) were grown in minimum essential medium- $\alpha$ (MEM- $\alpha$ ) supplemented with $20 \%$ fetal bovine serum (FBS) and antibiotics. Cells were seeded at the density of $2 \times 10^{5} / \mathrm{mL}$.

RA (Sigma Aldrish) was used at a final concentration of $1 \mu \mathrm{M}$. The Pin1 inhibitor AG17724 (Sigma Aldrish) was used at $20 \mu \mathrm{M}$. Doxorubicin (Ebewe Pharma) and cytarabine (AraC) (Alexan, Ebewe Pharma) were each used at a final concentration of $1 \mu \mathrm{M}$. Cell growth was assessed using the trypan blue dye assay.

\section{Patients' cells}

Primary bone marrow blasts from AML patients were extracted following Ficoll separation and cultured in MEM- $\alpha$ supplemented with $20 \%$ FBS and antibiotics. Patients' samples were collected following approval by the American University of Beirut Institutional Review Board and after patients had provided written informed consent in accordance with the Declaration of Helsinki. The patients' characteristics are summarized in Online Supplementary Table S1.

Two AML patients with NPM-1c mutations who were judged unfit for conventional chemotherapy received off-label compassionate RA ( $25 \mathrm{mg} / \mathrm{m}^{2}$ daily) and ATO $(0.15 \mathrm{mg} / \mathrm{kg}$ daily) after informed consent.

\section{CRISPR OCI-AML3 cell lines}

PML expression was abrogated by CRISPR-mediated excision. A guide RNA targeting PML (forward: 5'-GTCGGTGTACCGGCAGATTG; reverse: 5'-AATCTGCCGGTACACCGAC) was designed and cloned into pLAS5w.Ppuro-Cas9 plasmid for viral packaging. OCI-AML3 cells were infected with the corresponding viruses. Stable selection of knock-out cells was performed in the presence of $1 \mu \mathrm{g} / \mathrm{mL}$ puromycin, over a period of 2 weeks. Three OCI-AML3 $3^{\text {pml- }}$ clones were generated and tested in this study. Similarly, P53 extinction was performed using a guide RNA targeting P53 (forward: 5'-CCATTGTTCAATATCGTCCG; reverse: 5'CGGACGATATTGAACAATGG). Recombinant Cas9 protein was synthesized from IDT to form Alt-R CRISPR/Cas9 RNP. OCIAML3 cells were transiently transfected with Alt-R CRISPR/Cas9 RNP by using Nucleofector kit T (Amaxa) and applied program number X-01 in the nucleofactor device (Lonza). The stable CRISPR knock-out clones were cloned by serial dilution to generate a single-cell separation. DNA from individual clones was extracted and the region surrounding the Cas9 cutting site was amplified by polymerase chain reaction and verified by sequencing to ensure the deletion of the target genes. Two OCI-AML3 ${ }^{\text {P53-1 }}$ clones were generated and tested in this study.

Pin1 knock-down was perfomed using all-in-one plasmid pLAS5w.Ppuro-Cas9-gPin1 Pin1 (CCACCGTCACACAGTATTTAT). Lentiviruses were produced by transient transfection of HEK-293T cells. OCI-AML3 cells were infected by spinoculation for $90 \mathrm{~min}$ at $28,000 \mathrm{rpm}$ at $32^{\circ} \mathrm{C}$. Stable selection of knock-out cells was performed in the presence of $1 \mu \mathrm{g} / \mathrm{mL}$ puromycin. Single cells were sorted in 96-well plate to have stable clones. Knock-out stable clones were verified by immunofluorescence and western blot using a polyclonal anti-Pin1 antibody (Cell Signaling).

\section{Statistical analysis}

Data are reported as means \pm standard deviations. Statistical analysis was done using a Student $t$-test, $P$-values $<0.05$ are considered statistically significant.

\section{Other methods}

Immunoblotting, RNA isolation and quantitative reverse transcriptase polymerase chain reaction, microarray analysis and gene set enrichment analysis, immunofluorescence and confocal microscopy, Pin1 activity assay, colony formation assay, xenograft animal studies, human CD45 staining and cell sorting are described in the Online Supplementary Methods.

\section{Results}

\section{PML-dependent NPM-1c degradation activates P53}

We and others demonstrated that RA triggers NPM-1c degradation, P53 activation, apoptosis and induces PML nuclear body formation in NPM-1c-expressing AML cell lines. ${ }^{1718}$ Since PML nuclear bodies may be implicated in therapy-induced catabolism of other oncoproteins, ${ }^{34}$ we were prompted to investigate any role of PML in RA-triggered NPM-1c degradation. We thus generated CRISPR PML OCI-AML3 cell lines (Figure 1A, Online Supplementary Figure S1A). In these OCI-AML3 ${ }^{\text {mlt- }}$ cells, RA-mediated NPM-1c degradation was blocked (Figure 1A, Online Supplementary Figure S1A) and RA-induced cell death was abrogated (Figure 1B, Online Supplementary Figure S1B). 
A

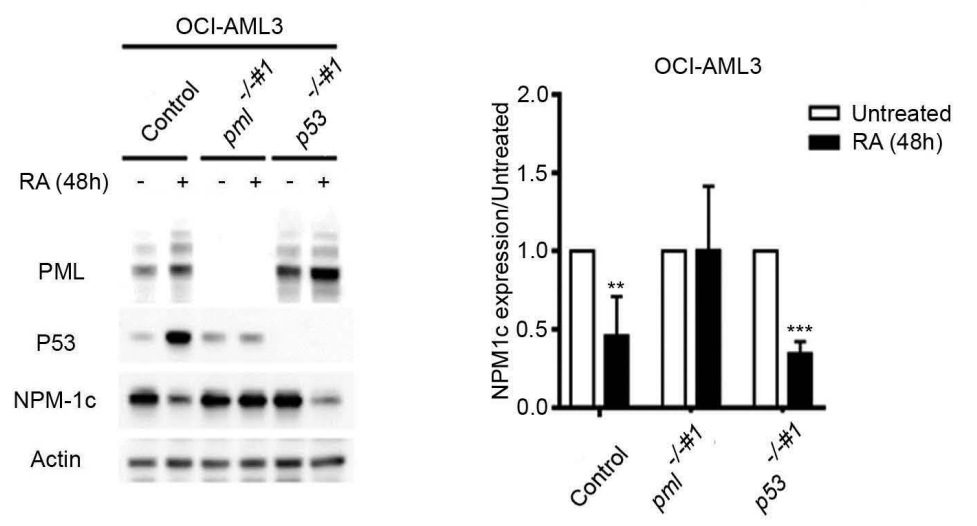

C
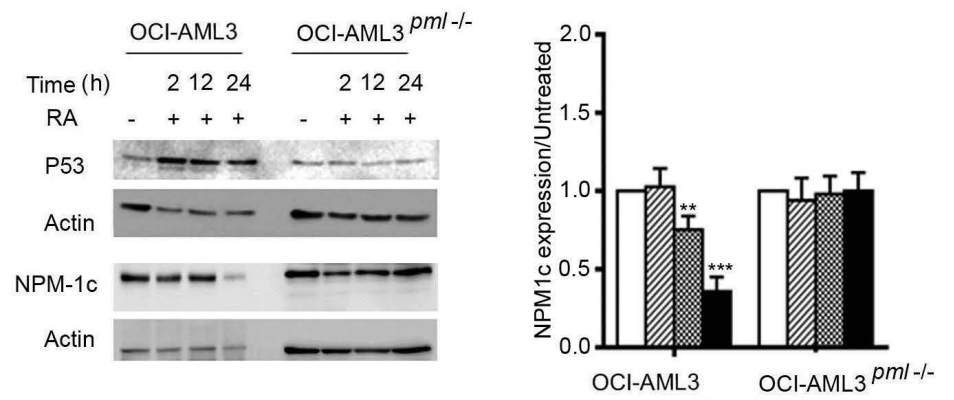

D

E
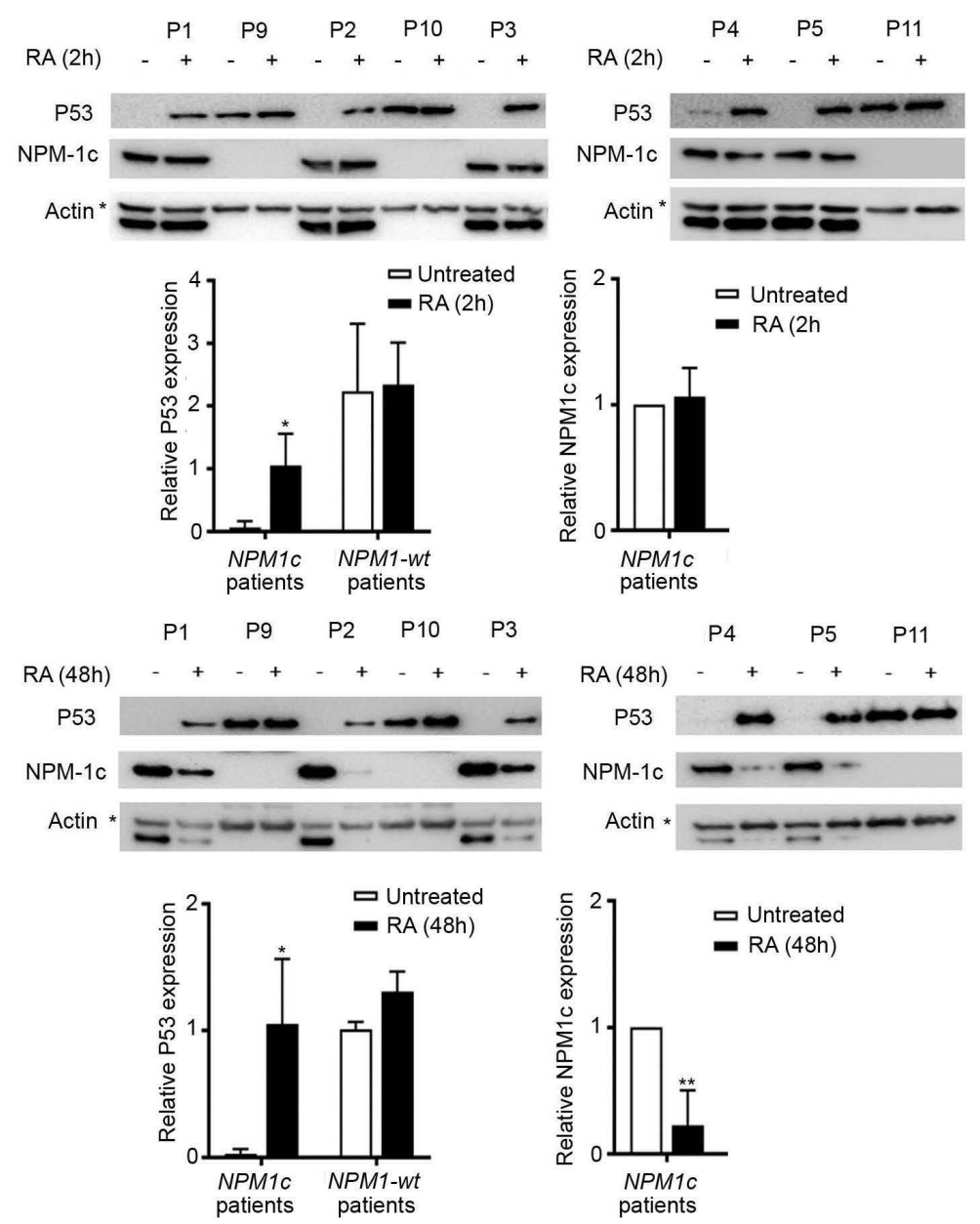

B
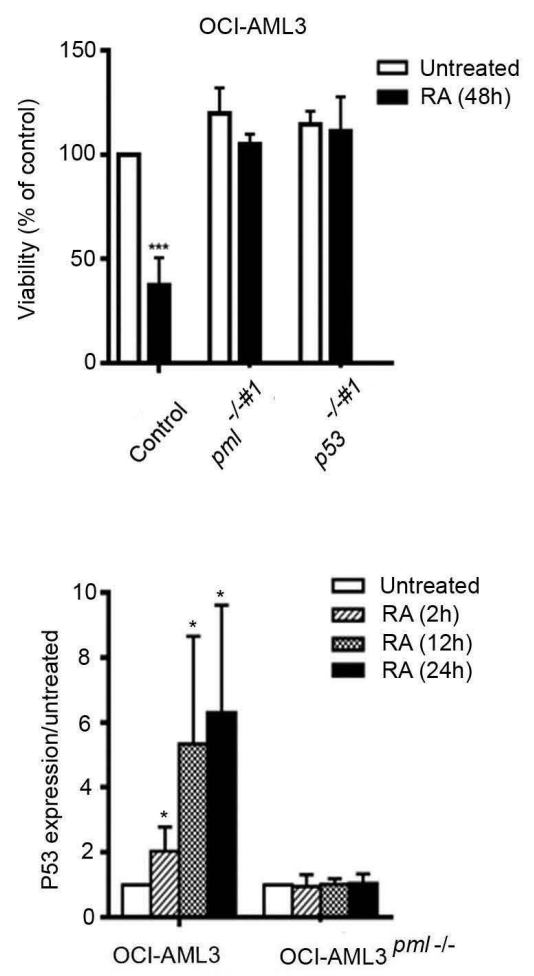

Figure 1. PML-dependent NPM-1c degradation and P53 activation. (A) Western blot analysis of PML, $\mathrm{P} 53$ and NPM-1C was performed on extracts of OCl$\mathrm{AML} 3$, one clone of $\mathrm{OCl}-\mathrm{AML} 3^{\mathrm{pml} / /-}\left(\mathrm{OCl}-\mathrm{AML} 3^{\mathrm{pml} / \# 1}\right)$ and one clone of OCl-AML $3^{\text {P53/\% }}\left(\mathrm{OCl}-\mathrm{AML} 3^{\text {P53/*\#1 }}\right)$ after treatment with retinoic acid (RA) for $48 \mathrm{~h}$. Densitometry histograms represent data from an average of five independent experiments. Densitometry was performed using ImageJ software. Statistical analysis was done using a Student $t$-test. (B) Cell growth (percent of control) was assessed using the trypan blue exclusion dye assay, in triplicate wells in $\mathrm{OCl}-\mathrm{AML} 3$, one clone of $\mathrm{OCl}$ $\mathrm{AML}^{\mathrm{pml} / \cdot-}\left(\mathrm{OCl}-\mathrm{AML} 3^{\mathrm{pml} / *+* 1}\right)$ and one clone of $\mathrm{OCl}$ $\mathrm{AML}^{\text {p53./ }}\left(\mathrm{OCl}-\mathrm{AML} 3^{\text {p53/-\#1 }}\right.$ ) following treatment with RA for $48 \mathrm{~h}(\mathrm{n}=3)$. (C) Western blot analysis of P53 and NPM-1C in OCl-AML3 and OCl-AML $3^{\text {pml } /-}$ after treatment with RA for 2,12 and $24 \mathrm{~h}$ as indicated. Densitometry histograms represent data from an average of three independent experiments. Densitometry was performed using ImageJ software. Statistical analysis was done using a Student $t$-test. (D) Western blot analysis of NPM-1c and P53 in primary blasts derived from five patients with NPM-1C acute myeloid leukemia (AML) and three NPM-1wt AML patients, after ex-vivo treatment with RA for $2 \mathrm{~h}$. Densitometry histograms represent average P53 and NPM-1c expression levels in five NPM1c AML patients and three NPM-1wt AML patients. Densitometry was performed using ImageJ software. Statistical analysis was done using a Student t-test. (E) Western blot analysis of NPM-1c and P53 in primary blasts derived from five NPM-1C AML patients and three NPM-1wt AML patients, after exvivo treatment with RA for $48 \mathrm{~h}$. Densitometry histograms represent average P53 and NPM-1c expression levels in five NPM-1C AML patients and three NPM-1wt AML patients. Densitometry was performed using ImageJ software. Statistical analysis was done using a Student t-test, $* P<0.05$; $* * P<0.01 ; * * * P<0.001$. 
A P9
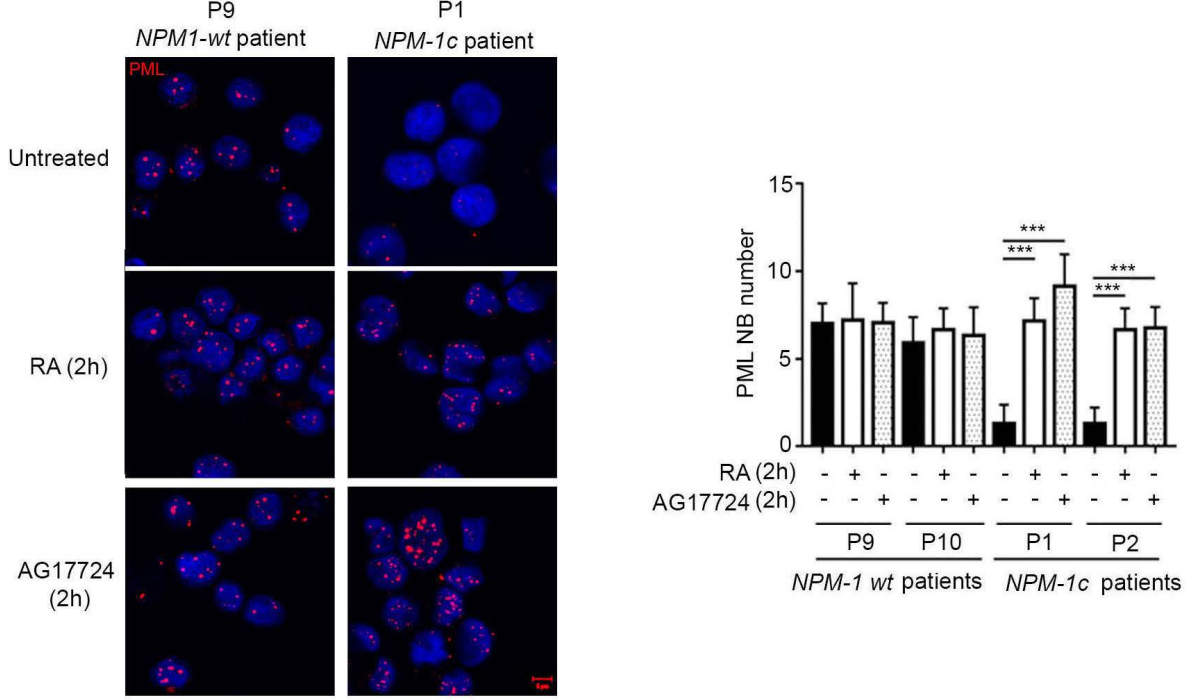

$$
\frac{\mathrm{P} 9}{\mathrm{P} 10} \frac{\mathrm{P} 1}{\mathrm{P} 2} \frac{\mathrm{P} 2}{\text { NPM-10 patients }}
$$

B
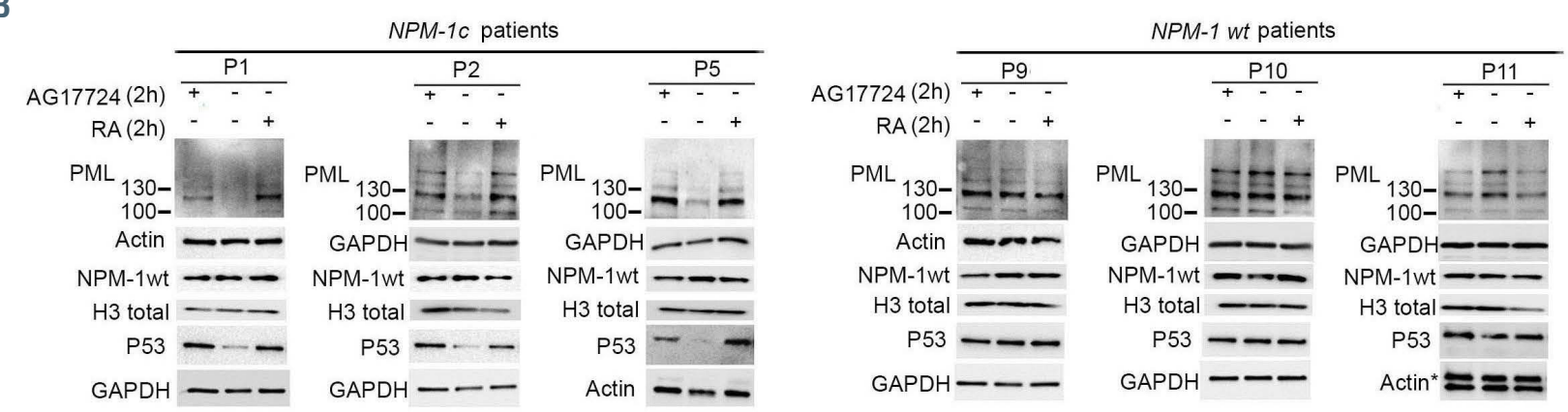

C

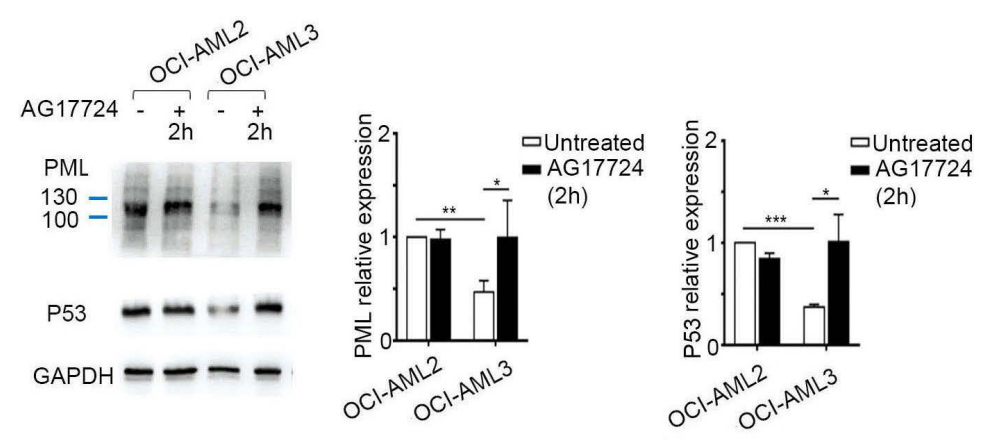

D

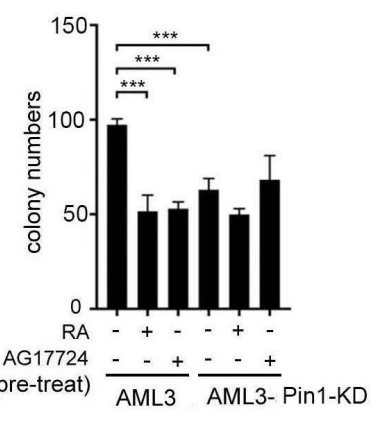

E
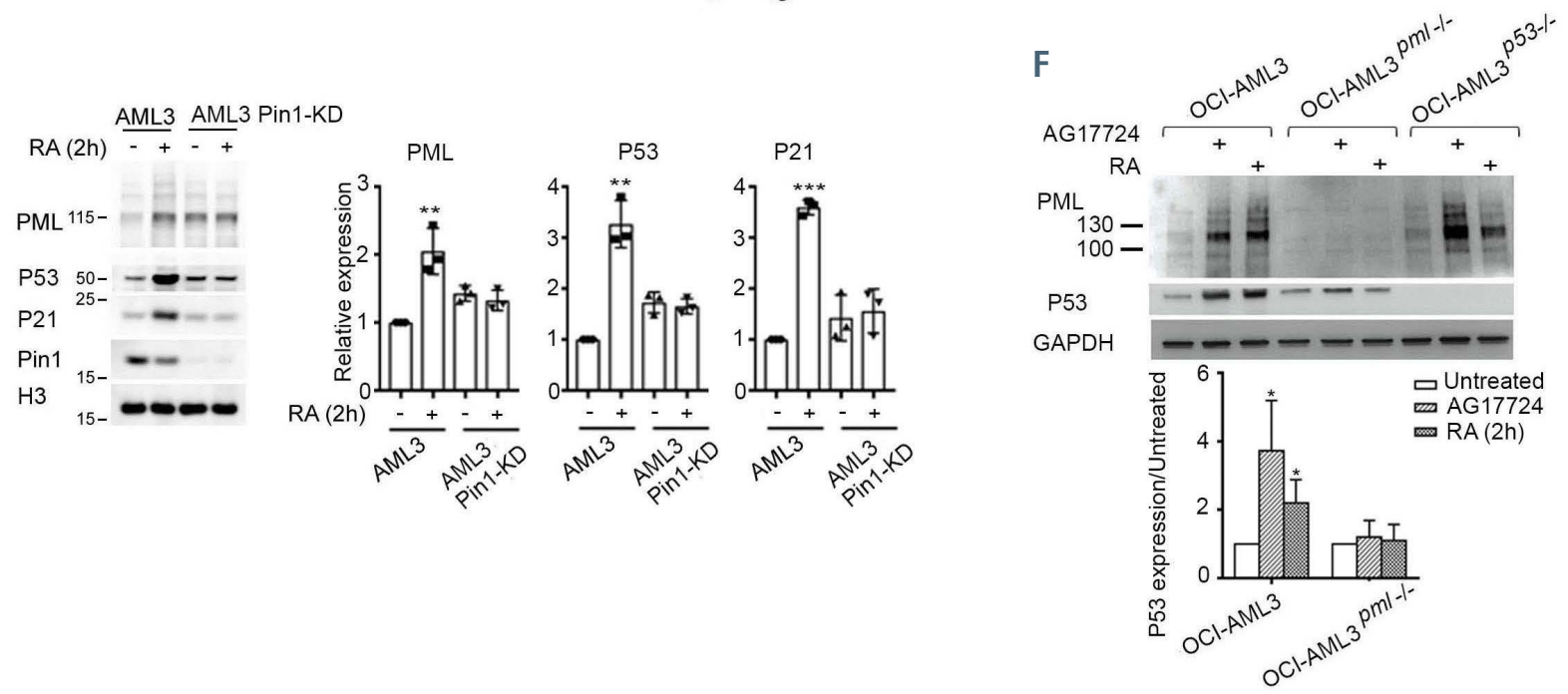

Figure 2. Legend on following page. 
Figure 2. Retinoic acid targets PML/P53 through Pin1 inactivation. (A) Confocal microscopy of PML-nuclear bodies (NB) in primary blasts derived from one representative acute myeloid leukemia (AML) patient with wild-type (wt) NPM-1 and one representative AML patient with mutated NPM-1c, after ex-vivo treatment with retinoic acid (RA) or AF-17724 for $2 \mathrm{~h}$ as indicated. Histograms represente average number of PML NB per cell in two patients with NPM-1 wt and two patients with mutated NPM-1c. Statistical analysis was done using a Student $t$-test. (B) Western blot analysis of PML, P53 and total NPM-1 (NPM1-wt) in primary blasts derived from three patients with NPM-1c AML and three patients with NPM-1 wt AML, after ex-vivo treatment with $20 \mu \mathrm{M}$ of AG17724 or $1 \mu \mathrm{M}$ of RA for $2 \mathrm{~h}$ as indicated. (C) Western blot of PML and P53 in OCl-AML3 and OCl-AML2 cells following treatment with $20 \mu \mathrm{M}$ of AG17724 for $2 \mathrm{~h}$. Densitometry histograms represent an average of three independent experiments. (D) Colony-formation assays in methylcellulose of OCl-AML3, and OCI-AML3 Pin1-knock down (KD) cells, pre-treated with RA or AG17724 for $3 \mathrm{~h}(\mathrm{n}=3)$. (E) Western blot analysis of PML, P53, P21, or Pin1 in OCl-AML3 and OCl-AML3 Pin1-KD after treatment with $1 \mu$ M of RA for $2 \mathrm{~h}$. Densitometry histograms represent an average of three independent experiments. Densitometry was performed using Image J software. Statistical analysis was done using a

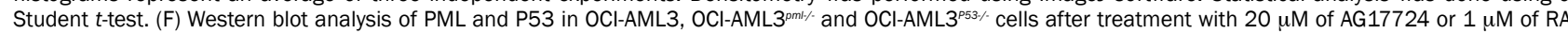
for $2 \mathrm{~h}$ as indicated. Densitometry histograms represent an average of three independent experiments. Densitometry was performed using Image $\mathrm{J}$ software. Statistical analysis was done using a Student $t$-test, $* P<0.05 ; * * P<0.01 ; * * * P<0.001$.

When assessing the transcriptional effects of RA treatment in OCI-AML3 and control OCI-AML2 cells, a clear P53 signature was noted in OCI-AML3 cells (Online Supplementary Figure $S 1 C-E$ ), in line with RA-induced P53 stabilization. ${ }^{17,18}$ To assess any role of P53 in cell death upon RA exposure, we also generated CRISPR P53 OCI-AML3 (OCI$\mathrm{AML}^{P 53-/}$ ) cell lines (Figure 1A, Online Supplementary Figure $S 1 F)$. In this model, RA again failed to initiate cell death (Figure 1B, Online Supplementary Figure S1G), although it efficiently degraded NPM-1c (Figure 1A, Online Supplementary Figure S1F). Collectively, the RA-triggered, PML-facilitated NPM-1c degradation likely explains P53 activation and growth arrest of AML cells.

\section{Retinoic acid targets P53 prior to NPM-1c loss}

Further investigating the kinetics of response to RA, we unexpectedly obtained evidence of rapid P53 stabilization prior to any significant NPM-1c loss, but with a requirement for PML expression (Figure 1C). Thus, NPM-1c loss is not the sole contributor to P53 activation. Remarkably, similar data were obtained upon ex vivo treatment of primary blasts derived from NPM-1c AML patients, in whom RA-triggered NPM-1c loss was only obtained after 48 h, while P53 stabilization was generally observed as soon as $2 \mathrm{~h}$ (Figure 1D, E). Critically, such RA-triggered P53 activation was solely observed in samples from patinets with NPM-1c AML (Figure 1D, E). Thus, delayed NPM-1c degradation is most unlikely to explain early P53 activation upon RA treatment.

\section{Retinoic acid stabilizes PML through Pin1 inactivation}

RA also rapidly stabilized PML levels and induced PML nuclear body formation, solely in NPM-1c-positive patients' blasts or OCI-AML3 cells, with kinetics closely resembling those of P53 stabilization (Figure 2A, Online Supplementary Figure S2A-C). RA inconsistently enhanced $P M L$ gene expression, possibly through increased interferon production. ${ }^{35}$ Previous studies have shown that RA inhibits the Pin1 enzyme and the latter regulates PML stability., 50,36 We thus compared the effects of RA and a Pin1 inhibitor (AG17724) on PML abundance, nuclear body formation and P53 activation. Strikingly, RA or AG17724 similarly stabilized PML or P53 levels and promoted nuclear body formation in NPM-1c AML patients' blasts and OCI-AML3 cells (Figure 2A-C, Online Supplementary Figure S2A-C). In contrast, NPM-1-WT AML cells were unresponsive to RA and AG17724 (Figure 2A-C, Online Supplementary Figure $S 2 A)$. Pin1 inhibition did not initiate NPM-1c degradation (Online Supplementary Figure S2D, E), implying that RAinduced PML stabilization is necessary, but not sufficient, to induce NPM-1c catabolism. Functionally, RA and AG17724 lead similarly to loss of clonogenic activity of OCI-AML3 cells in methyl-cellulose (Figure 2D). For a direct demonstration of the involvement of Pin1 in the response to RA, we generated an OCI-AML3 cell line with stable Pin1 downregulation by shRNA. Downregulation of Pin1 did not affect the viability of NPM-1c AML cells (Online Supplementary Figure S2F). Remarkably, PML and P53 or P21 activation by RA was abrogated following downregulation of Pin1 (Figure 2E), and RA-induced cell death was lost (Online Supplementary Figure $2 F$ ). Loss of clonogenic activity by RA or Pin1 inhibition was also abrogated (Figure 2D). Thus, RA-induced activation of P53 and resulting growth arrest are initiated by Pin1 inhibition.

\section{PML is the primary target of retinoic acid and Pin1 inhibitors}

Pin1 directly controls both the stability of PML and P53 signaling. ${ }^{37}$ PML and P53 are highly cross-regulated: PML controls P53 activation, but P53 transcriptionally induces PML expression. ${ }^{38,39}$ To decipher the respective roles of PML and P53 in response to Pin1, we compared the responses to RA and AG17724 in OCI-AML3 and its pmt and P53 derivatives. Both drugs upregulated PML levels in $P 53^{-1}$ cells, and no (or minimal) induction of P53 was observed in OCIAML3 $^{\text {pml-/ }}$ cells (Figure $2 \mathrm{~F}$ ). These results establish that PML is the primary target of Pin1 inhibition in NPM-1c-expressing cells. These results support a model wherein RA inactivates Pin1, to stabilize PML, induce nuclear body formation, activate P53 and suppress growth. This does not exclude the possibility that P53 then constitutes a feed-forward amplification loop on PML expression.

\section{NPM-1c-expressing cells exhibit high basal level and activity of Pin1}

The implication of Pin1 inhibition in RA-mediated effects in NPM-1c-expressing cells prompted us to investigate Pin1 levels and activity. Strikingly, high Pin1 protein levels and activity were observed in NPM-1c-expressing cell lines and primary blasts (Figure 3A-C, Online Supplementary Figure $S 3 A)$. Treatment with RA significantly reduced Pin1 activity (Figure 3C) without affecting Pin1 protein level (Online Supplementary Figure $S 3 B$ ). In line with this increased Pin1 protein level and activity in NPM-1c-expressing cells, both RA and AG17724 synergized with arsenic trioxide (ATO), and standard chemotherapy drugs used in AML, doxorubicin or cytarabine, to induce death of OCI-AML3 cells but not of OCI-AML2 cells (Figure 3D).

\section{Retinoic acid and chemotherapy cooperate to clear NPM-1c-expressing cells in vivo}

The clinical benefit of co-administration of RA with chemotherapy seems restricted to AML bearing an NPM-1c mutation. ${ }^{16}$ We thus examined the possibility of in vivo cooperation between RA and standard-of-care AML therapy, anthracyclins and cytarabine, and examined any $P M L$ dependency. We used xenografts from OCI-AML3 or OCI- 
AML3 ${ }^{\text {pml- }}$, which were treated or not with RA for 1 week followed by either doxorubicin or cytarabine as single agents, for an additional 1 week. RA induced PML-dependent NPM-1c downregulation and human P53 stabilization in vivo (Figure 4A-D), while all three drugs ultimately induced human P53 phosphorylation (Figure 4A, B).

A

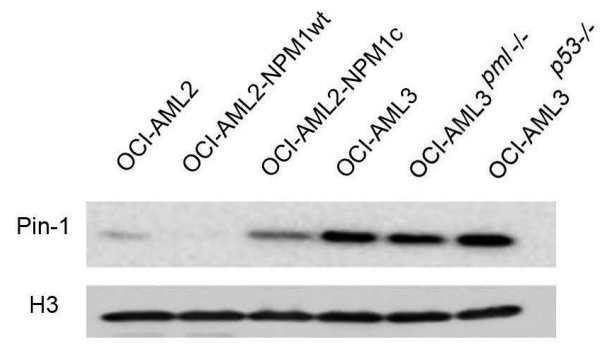

B

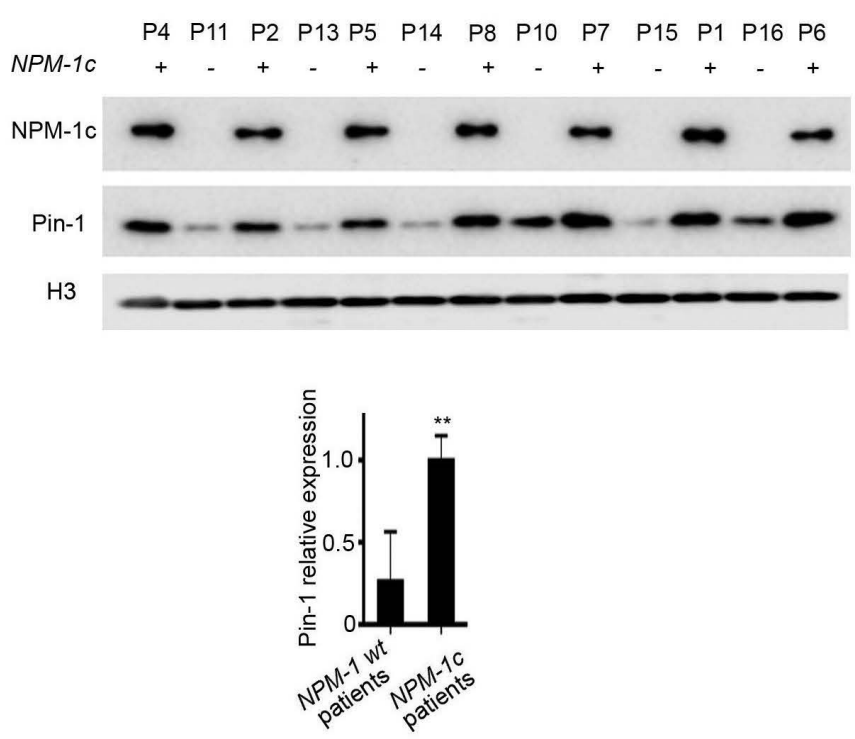

C

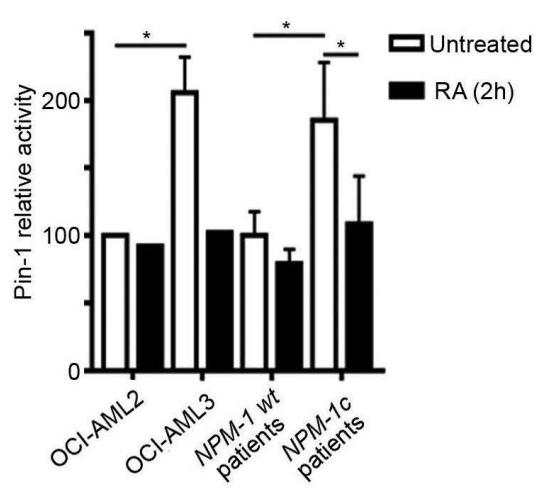

Importantly, RA synergized with doxorubicin or cytarabine to decrease abundance of human cells in treated mice, only in cells bearing intact PML (Figure 4E-H). These observations suggest that, at least in this model, RA cooperates with chemotherapy to decrease AML burden, resembling the clinical observations made in AML.
D
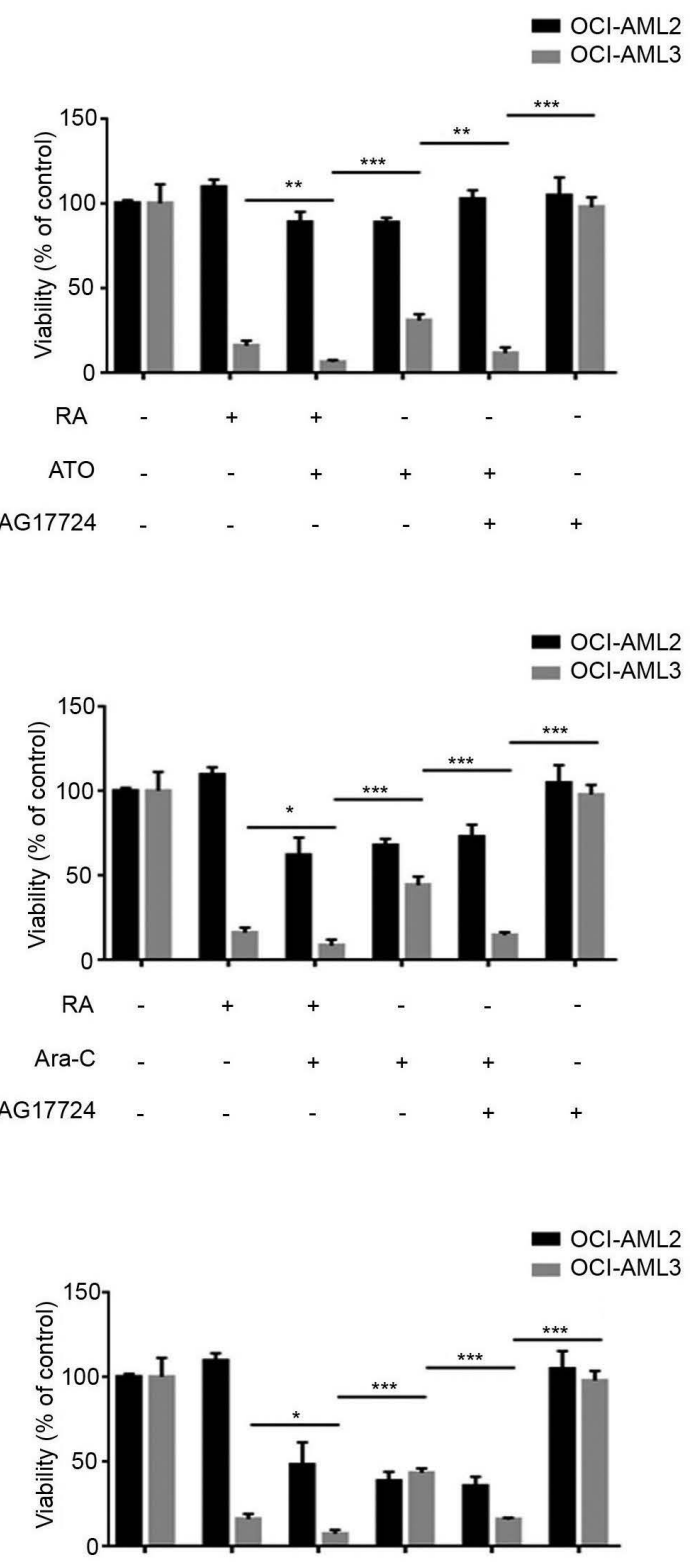

Doxorubicin

AG17724

Figure 3. NPM-1c-expressing cells exhibit high Pin1 level and activity. (A) Western blot analysis of Pin1 in OCI-AML2, OCI-AML2-NPM-1wt, OCI-AML2-NPM-1c, OCl-

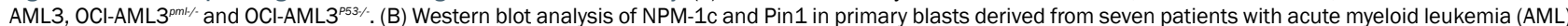
with NPM-1c (p4, p2, p5, p8, p7, p1 and p6) and six AML patients with wild-type NPM-1 (NPM-1 wt) (p11, p13, p14, p10, p15 and p16). Densitometry histograms represent an average of Pin1 expression level in the seven tested NPM-1c AML patients and the six tested NPM-1 wt AML patients. Densitometry was performed using Image J software. Statistical analysis was done using a Student $t$-test. (C) Pin1 relative activity in OCl-AML2, OCl-AML3 and in primary blasts derived from three NPM-1c AML patients and two NPM-1 wt AML patients after treatment with $1 \mu \mathrm{M}$ of RA, as indicated. Statistical analysis was done using a Student $t$-test. (D) Cell growth (percent of control) was assessed using the trypan blue exclusion dye assay in OCI-AML2 and OCI-AML3 cells following treatment with RA alone, AG-17724 alone or their combination with arsenic trioxide (ATO), cytarabine (Ara-C) and doxorubicin for $72 \mathrm{~h}$ as indicated $(n=3)$. Statistical analysis was done using a Student t-test, $* P<0.05 ; * * P<0.01 ; * * * P<0.001$. 
A

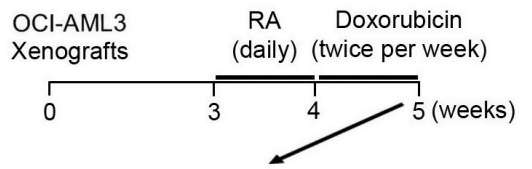

hCD45 sorted cells

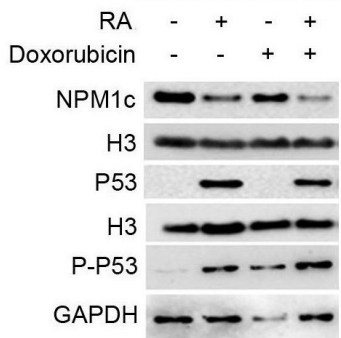

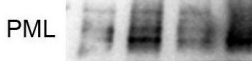

GAPDH $-\longrightarrow$

OCI-AML3

C

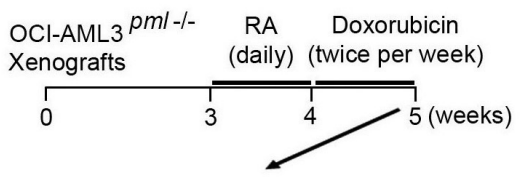

hCD45 sorted cells

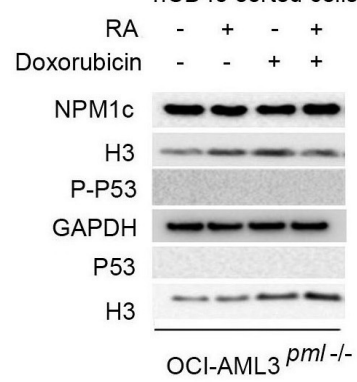

E

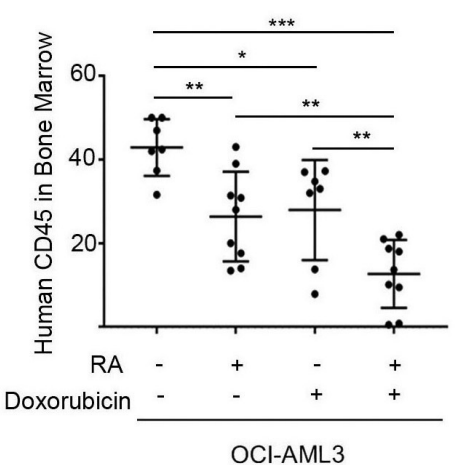

G

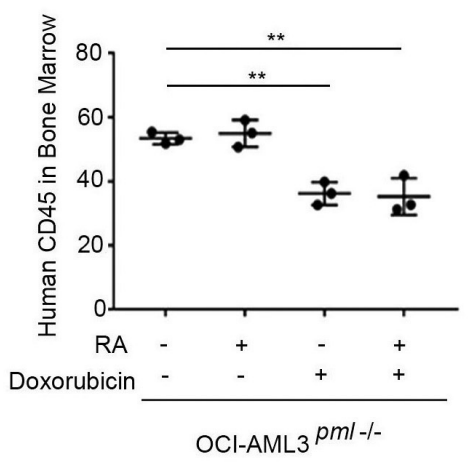

B

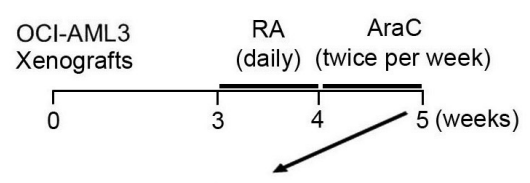

hCD45 sorted cells

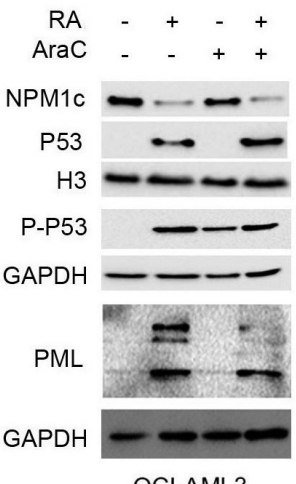

OCI-AML3

D OCl-AML3 $^{p m /-/-}$ RA AraC

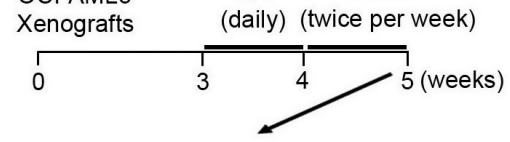

hCD45 sorted cells

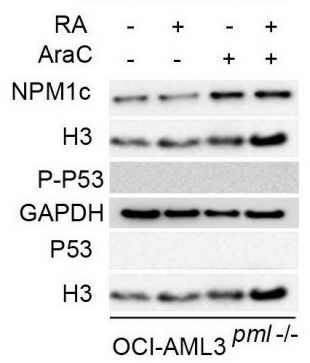

F

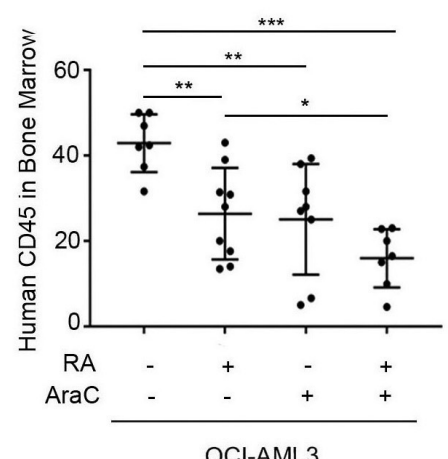

H

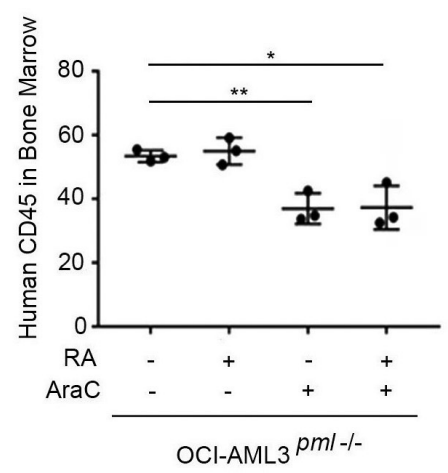

Figure 4. Retinoic acid and chemotherapy cooperate to clear NPM-1c-expressing cells in vivo. (A, B) Eight-week-old NSG mice were injected with $2 \times 10^{6} \mathrm{OCl}$ AML3 cells intravenously. At day 21 after injection of the leukemic cells, retinoic acid (RA) was administered on a daily basis at the dose of $2.5 \mathrm{\mu g} / \mathrm{g}$ over a period of 1 week, followed by the administration of doxorubicin $(2 \mu \mathrm{g} / \mathrm{g})$ or cytarabine (AraC) $(60 \mu \mathrm{g} / \mathrm{g})$ twice a week over a period of 1 week. Mice were sacrificed, Bone marrow was harvested from femura and tibiae of xenografted mice and then stained with anti-human CD45 (hCD45) antibody. Western blot of NPM-1c, human P53, human P-P53 and PML in sorted hCD45-positive cells from $\mathrm{BM}$ harvested from untreated or treated NSG xenografted mice as indicated (2 mice per condition). (C, D) Eight-weekold NSG mice were intravenously injected with $2 \times 10^{6} \mathrm{OCl}^{-\mathrm{AML}^{\mathrm{mml} /}}$ cells. The same treatment regimen was followed as indicated above. Western blot of NPM-1c, human P53 and P-P53 in sorted hCD45-positive cells from bone marrow harvested from untreated or treated $N S G$ xenografted mice as indicated. (E, F) Graphs showing the percentage of hCD45 cells in OCl-AML3 xenografted NSG mice treated as described above ( 7 mice in the untreated group and in the groups treated with doxorubicin alone or RA in combination with cytarabine [AraC], 9 mice in the group treated with RA alone or doxorubicin and RA, 8 mice in the group treated with cytarabine alone). (G, H) Graphs showing the percentage of hCD45 cells in OCl-AML ${ }^{\text {pml. }}$ xenografted NSG animals treated as described above (3 mice in each condition). 
A

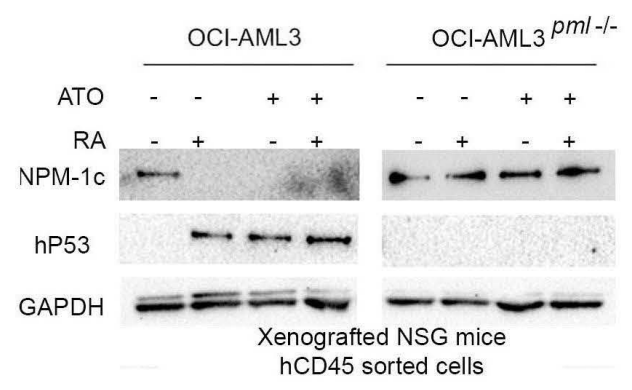

C Newly diagnosed
NPM-1c FLT3-ITD

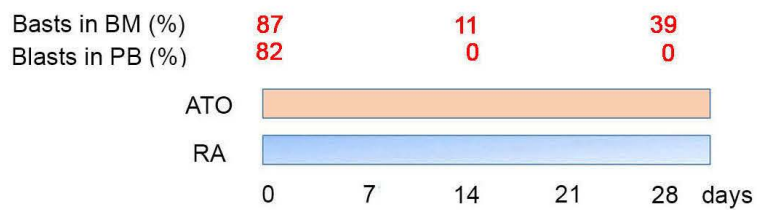

B

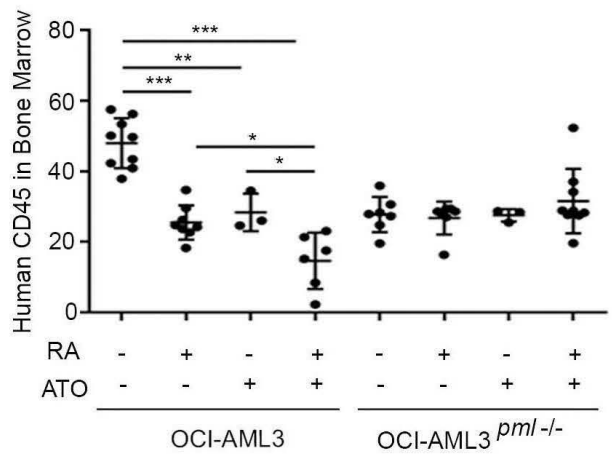

P18

Relapsed NPM1c FLT3wt

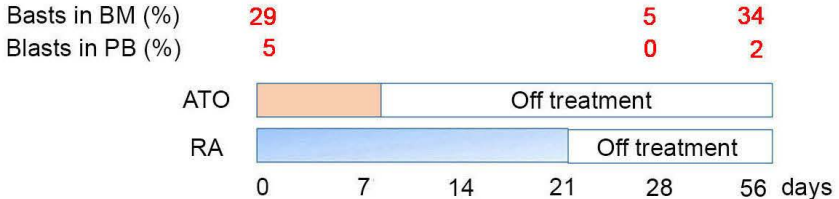

D

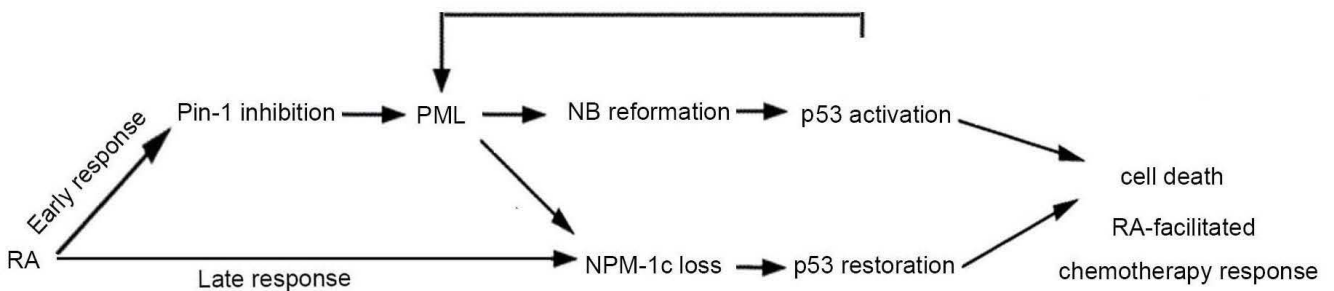

Figure 5. Retinoic acid and arsenic cooperate to clear NPM-1c-expressing cells. (A) Eight-week-old NSG mice were injected with $3 \times 10^{6}$ OCl-AML3 or OCl-AML $3^{\text {pmt. }}$ cells intravenously. From day 7 after injection of the leukemic cells, arsenic trioxide (ATO, $5 \mu \mathrm{g} / \mathrm{g} /$ day) and retinoic acid (RA, $2.5 \mu \mathrm{g} / \mathrm{g}$ ) were administered intraperitoneally every other day, over a period of 4 weeks. Western blot of human P53 and NPM-1c in sorted hCD45 positive bone marrow (BM) cells from NSG mice xenografted with OCl-AML3 or OCl-AML3 ${ }^{\text {pml- }}$ cells, after in vivo treatment with ATO alone, RA alone or the combination of RA and ATO. (B) Eight-week-old NSG mice were injected with $3 \times 10^{6}$ OCI-AML3 or OCl-AML $3^{\text {pml- }}$ cells intravenously. From day 7 after injection of the leukemic cells, ATO and RA were administered every other day, over a period of 4 weeks intraperitoneally. At the end of treatment, bone marrow was harvested from femora and tibiae of xenografted mice and then stained with anti-hCD45 antibody. Graphs show the percentage of hCD45 cells in xenografted animals. (C) Treatment schedule in two patients with NPM-1c mutated acute myeloid leukemia (AML) treated with RA and ATO as indicated. Percentages of peripheral blood (PB) and bone marrow (BM) blasts are displayed. (D) Proposed model of the molecular mechanisms of the response of NPM-1C AML to RA. ITD: internal tandem duplication; NB: nuclear body.

\section{The combination of retinoic acid and arsenic trioxide has clinical activity in mice and patients with acute myeloid leukemia}

RA and ATO trigger NPM-1c degradation, P53 activation and apoptosis in NPM-1c-expressing AML cell lines..$^{17,18} \mathrm{RA}$ upregulates PML, while ATO targets PML to enforce nuclear body formation and also inhibits Pin $1 .{ }^{6}$ Thus, in principle, ATO could cooperate with RA through PML nuclear body targeting. ${ }^{19}$ To explore any in vivo relevance of these findings, we treated xenografts from OCI-AML3 or OCI-AML3 $3^{\text {pml- }}$ with RA and ATO for 1 week. RA/ATO induced PML-dependent NPM-1c degradation and human P53 stabilization in vivo (Figure 5A) and decreased abundance of human cells in treated mice, again solely in cells bearing intact PML (Figure 5B).

The combination of RA/ATO is a very well-tolerated therapeutic association in APL.40 Two NPM-1c AML patients, unfit for conventional therapy, received this RA/ATO combination on an off-label compassionate basis. Blast clearance from peripheral blood and, to a lesser extent, from bone marrow was observed, although complete remission was not achieved (Figure 5C). Longer follow-up after 2 months showed appearance of slowly growing AML cells. Thus, the RA/ATO combination may transiently target AML cells in some NPM-1c-mutated patients.

\section{Discussion}

The basis for sensitivity of non-APL AML to RA was initially believed to be RA-induced differentiation. ${ }^{11,41}$ Here we report that PML constitutes an unsuspected actor downstream of RA and is required for its synergistic activity with other therapies in NPM-1c AML models. Previous ex vivo studies suggested that RA-driven NPM-1c degradation could be the molecular basis of the therapeutic activity of this drug through upregulation of ARF and resulting activation of P53. NPM-1c degradation should also correct multiple other phenotypes associated with NPM-1c, including sequestration of key regulators in the cytoplasm or transcriptional deregulation. ${ }^{4,42-45}$ Here, kinetic analysis of P53 activation upon RA treatment revealed that P53 
upregulation actually precedes NPM-1c loss, which is suggestive of the existence of at least another pathway of P53 activation. Indeed we found that RA plays an essential role in growth arrest through Pin1 inhibition in both OCIAML3 and primary patients' blasts of NPM-1c AML cells only. Downstream of Pin1 inhibition, we identified the PML and P53 growth suppressors as its essential downstream effectors. ${ }^{36,46}$ Analysis of $\mathrm{pmt}^{-1}$ and $\mathrm{P} 53^{-1}$ AML3 cells demonstrated that P53 is downstream of PML-triggered Pin1 or RA responses. Our discovery of the key role of PML downstream of RA-initiated Pin1 inhibition (Figure 5D) suggests that RA-initiated Pin1 inhibition would upregulate PML and promote PML nuclear body formation, ultimately driving $\mathrm{P} 53 /$ senescence. These results suggest that in NPM-1c-driven AML, but not in NPM1-WT AML, impairment of PML nuclear body formation is involved in leukemic transformation and that RA-mediated restoration of PML nuclear bodies contributes to the therapeutic effects.

In NPM-1c-positive AML, elucidation of the respective contributions of PML nuclear bodies and NPM-1c degradation in the in vivo response, notably in combination with conventional chemotherapy, requires further investigations. Yet, the absence of an effect of RA on clonogenic activity of Pin1 downregulated AML cells favors an important role of Pin1 inhibition in biological response and not only early P53 activation (Figure 2D). This model has several feed-forward loops, all favoring anti-proliferative responses: RA-induced PML stabilization should facilitate PML-dependent NPM-1c degradation and P53 activation will enhance PML expression. Our results unravel a parallelism with the APL model: both involve oncoproteins that downregulate basal P53 signaling. In both, therapy response involves degradation of the driv- ing oncogene, PML nuclear body formation and P53 activation. $^{8}$ The co-existence of other major oncogenes (epigenetic regulators, FLT3) in NPM-1c-positive AML most likely explains why RA/ATO is not curative on its own. Nevertheless, RA could favor the action of chemotherapy, possibly by reverting basal Pin 1 activation and P53 inhibition. Our observations could explain the clinical benefit of the co-administration of RA with conventional chemotherapy in NPM-1c-positive AML. ${ }^{13,16}$ More broadly, the RA/ATO combination could target malignancies in which Pin1 and/or PML are deregulated. ${ }^{26,27}$ In this respect, clinical responses by solid tumors were observed in some RA/ATO-treated APL patients who had another synchronous malignancy, ${ }^{47,48}$ possibly reflecting activation of the RA/Pin1/PML/P53 axis elucidated by this study.

\section{Disclosures}

No conflicts of interest to disclose.

\section{Contributions}

$R H, H C W$, and $C B$ performed experiments; $Z H H$ treated patients; $R M$ collected bone marrow samples; $R H, H E H, H C W$, $C B, Z C, M E S, H d T$, and $A B$. analyzed results; $R H, H E H$, $H C W$, and $C B$ created the figures; $H E H, A B$, and $H d T$ designed the research and wrote the paper.

\section{Funding}

This work was supported by the American University of Beirut (AUB) and the Lebanese National Council for Scientific Research (CNRSL) (Group Research Proposal GRP AUB-CNRSL) (to $H E H$ and $A B)$; the Paris laboratory is supported by INSERM, CNRS, College de France, Université de Paris, Ligue Contre le Cancer, TRANSCAN, CAMELIA, The Sjoberg Foundation, and Foundation St. Joseph.

\section{References}

1. Grisendi S, Mecucci C, Falini B, Pandolfi PP. Nucleophosmin and cancer. Nat Rev Cancer. 2006;6(7):493-505.

2. Falini B, Nicoletti I, Martelli MF, Mecucci C. Acute myeloid leukemia carrying cytoplasmic/mutated nucleophosmin (NPMc+ AML): biologic and clinical features. Blood. 2007;109(3):874-885.

3. Heath EM, Chan SM, Minden MD, Murphy T, Shlush LI, Schimmer AD. Biological and clinical consequences of NPM1 mutations in AML. Leukemia. 2017;31(4):798-807.

4. Kunchala P, Kuravi S, Jensen R, McGuirk J, Balusu R. When the good go bad: mutant NPM1 in acute myeloid leukemia. Blood Rev. 2018;32(3):167-183.

5. Wei S, Kozono S, Kats L, et al. Active Pin1 is a key target of all-trans retinoic acid in acute promyelocytic leukemia and breast cancer. Nat Med. 2015;21(5):457-466.

6. Kozono S, Lin YM, Seo HS, et al. Arsenic targets Pin1 and cooperates with retinoic acid to inhibit cancer-driving pathways and tumor-initiating cells. Nat Commun. 2018;9(1):3069.

7. de The H. Differentiation therapy revisited. Nat Rev Cancer. 2018;18(2):117-127.

8. de The H, Pandolfi PP, Chen Z. Acute promyelocytic leukemia: a paradigm for oncoprotein-targeted cure. Cancer Cell. 2017;32(5):552-560.

9. Ablain J, Rice K, Soilihi H, de Reynies A, Minucci $S$, de The $H$. Activation of a promyelocytic leukemia-tumor protein 53 axis underlies acute promyelocytic leukemia cure. Nat Med. 2014;20(2):167-174.

10. Lehmann-Che J, Bally C, Letouzé E, et al. Dual origin of relapses in retinoic-acid resistant acute promyelocytic leukemia. Nat Commun. 2018;9(1):2047

11. Boutzen H, Saland E, Larrue C, et al. Isocitrate dehydrogenase 1 mutations prime the all-trans retinoic acid myeloid differentiation pathway in acute myeloid leukemia. Exp Med. 2016;213(4):483-497.

12. Altucci L, Rossin A, Hirsch O, et al. Rexinoid-triggered differentiation and tumours selective apoptosis of AML by protein kinase-A-mediated de-subordination of RXR. Cancer Res. 2005;65(19):8754-8765.

13. Schlenk RF, Frohling S, Hartmann F, et al Phase III study of all-trans retinoic acid in previously untreated patients 61 years or older with acute myeloid leukemia. Leukemia. 2004;18(11):1798-1803.

14. Burnett AK, Milligan D Prentice AG, et al. A comparison of low-dose cytarabine and hydroxyurea with or without all-trans retinoic acid for acute myeloid leukemia and high-risk myelodysplastic syndrome in patients not considered fit for intensive treatment. Cancer. 2007;109(6):1114-1124.

15. Milligan DW, Wheatley K, Littlewood T, Craig JI, Burnett AK, NCRI Haematological Oncology Clinical Studies Group. Fludarabine and cytosine are less effective than standard ADE chemotherapy in highrisk acute myeloid leukemia, and addition of G-CSF and ATRA are not beneficial: results of the MRC AML-HR randomized trial. Blood. 2006;107(12):4614-4622.

16. Schlenk RF, Dohner K, Kneba M, et al. Gene mutations and response to treatment with all-trans retinoic acid in elderly patients with acute myeloid leukemia. Results from the AMLSG Trial AML HD98B. Haematologica. 2009;94(1):54-60.

17. Martelli MP, Gionfriddo I, Mezzasoma F, et al. Arsenic trioxide and all-trans retinoic acid target NPM1 mutant oncoprotein levels and induce apoptosis in NPM1-mutated AML cells. Blood. 2015;125(22):3455-3465

18. El Hajj H, Dassouki Z, Berthier C, et al. Retinoic acid and arsenic trioxide trigger degradation of mutated NPM1, resulting in apoptosis of AML cells. Blood. 2015;125 (22):3447-3454.

19. Mugoni V, Panella R, Cheloni G, et al Vulnerabilities in $\mathrm{mIDH} 2 \mathrm{AML}$ confer sensitivity to APL-like targeted combination therapy. Cell Res. 2019;29(6):446-459.

20. Lallemand-Breitenbach V, de The H. PML nuclear bodies: from architecture to function. Curr Opin Cell Biol. 2018;52:154-161.

21. Niwa-Kawakita M, Ferhi O, Soilihi H, Le Bras M, Lallemand-Breitenbach V, de The H. PML is a ROS sensor activating P53 upon oxidative stress. J Exp Med. 2017;214(11): 3197-3206.

22. Zhu J, Koken MHM, Quignon F, et al Arsenic-induced PML targeting onto nuclear bodies: implications for the treatment of acute promyelocytic leukemia. Proc Natl 
Acad Sci U S A. 1997;94(8):3978-3983.

23. Lehmann-Che J, Bally C, de The H. therapy resistance in APL. $\mathrm{N}$ Engl J Med. 2014;371(12):1171-1172.

24. Lehmann-Che J, Bally C, Letouze E, et al. Dual origin of relapses in retinoic-acid resistant acute promyelocytic leukemia. Nat Commun. 2018;9(1):2047.

25. Jeanne M, Lallemand-Breitenbach V, Ferhi $\mathrm{O}$, et al. PML/RARA oxidation and arsenic binding initiate the antileukemia response of As2O3. Cancer Cell. 2010;18(1):88-98.

26. Koken MHM, Linares-Cruz G, Quignon F, et al. The PML growth-suppressor has an altered expression in human oncogenesis. Oncogene. 1995;10(7):1315-1324.

27. Gurrieri C, Capodieci P, Bernardi R, et al. Loss of the tumor suppressor PML in human cancers of multiple histologic origins. J Natl Cancer Inst. 2004:96(4):269-279.

28. Scaglioni PP, Yung TM, Cai LF, et al. A CK2dependent mechanism for degradation of the PML tumor suppressor. Cell. 2006;126 (2):269-283.

29. Wu HC, Lin YC, Liu CH, et al. USP11 regulates PML stability to control Notch-induced malignancy in brain tumours. Nat Commun. 2014;5:3214.

30. Yuan WC, Lee YR, Huang SF, et al. A Cullin3-KLHL20 ubiquitin ligase-dependent pathway targets PML to potentiate HIF-1 signaling and prostate cancer progression. Cancer Cell. 2011;20(2):214-228.

31. Fischer M. Census and evaluation of P53 target genes. Oncogene. 2017;36(28):39433956.

32. Lallemand-Breitenbach V, Jeanne $M$, Benhenda $S$, et al. Arsenic degrades PML or PML-RARalpha through a SUMO-triggered RNF4/ubiquitin-mediated pathway. Nat Cell Biol. 2008;10(5):547-555.
33. Nabbouh AI, Hleihel RS, Saliba JL, et al Imidazoquinoxaline derivative EAPB0503: promising drug targeting mutant nucleophosmin 1 in acute myeloid leukemia. Cancer. 2017;123(9):1662-1673.

34. Dassouki Z, Sahin U, El Hajj H, et al. ATL response to arsenic/interferon therapy is triggered by SUMO/PML/RNF4-dependent Tax degradation. Blood. 2015;125(3):474482.

35. Stadler M, Chelbi-Alix MK, Koken MHM, et al. Transcriptional induction of the PML growth suppressor gene by interferons is mediated through an ISRE and a GAS element. Oncogene. 1995;11(12):2565-2573.

36. Reineke EL, Lam M, Liu $Q$, et al Degradation of the tumor suppressor PML by Pin 1 contributes to the cancer phenotype of breast cancer MDA-MB-231 cells. Mol Cell Biol. 2008:28(3):997-1006.

37. Mantovani F, Zannini A, Rustighi A, Del Sal $\mathrm{G}$. Interaction of $\mathrm{P} 53$ with prolyl isomerases: healthy and unhealthy relationships. Biochim Biophys Acta. 2015;1850(10):20482060.

38. Pearson M, Carbone R, Sebastiani C, et al PML regulates P53 acetylation and premature senescence induced by oncogenic Ras Nature. 2000:406(6792):207-210.

39. de Stanchina E, Querido E, Narita M, et al. PML is a direct P53 target that modulates P53 effector functions. Mol Cell. 2004;13(4): 523-535

40. Lo-Coco F, Di Donato L: GIMEMA, Schlenk RF: German-Austrian Acute Myeloid Leukemia Study Group and Study Alliance Leukemia. Targeted therapy alone for acute promyelocytic leukemia. N Engl J Med. 2016;374(12):1197-1198.

41. Altucci L, Rossin A, Hirsch O, et al. Rexinoid-triggered differentiation and tumor-selective apoptosis of acute myeloid leukemia by protein kinase A-mediated desubordination of retinoid $\mathrm{X}$ receptor Cancer Res. 2005;65(19):8754-8765.

42. Gu X, Ebrahem O, Mahfouz RZ, et al. Leukemogenic nucleophosmin mutation disrupts the transcription factor hub that regulates granulomonocytic fates. J Clin Invest. 2018;128(10):4260-4279

43. Haindl M, Harasim T, Eick D, Muller S. The nucleolar SUMO-specific protease SENP3 reverses SUMO modification of nucleophosmin and is required for rRNA processing. EMBO Rep. 2008:9(3):273-279.

44. Kuo ML, den Besten W, Thomas MC, Sherr CJ. Arf-induced turnover of the nucleolar nucleophosmin-associated SUMO-2/3 protease Senp3. Cell Cycle. 2008;7(21):33783387

45. Yun C, Wang Y, Mukhopadhyay D, et al Nucleolar protein B23/nucleophosmin regulates the vertebrate SUMO pathway through SENP3 and SENP5 proteases. J Cell Biol. 2008;183(4):589-595

46. Lim JH, Liu Y, Reineke E, Kao HY. Mitogenactivated protein kinase extracellular signalregulated kinase 2 phosphorylates and promotes Pin1 protein-dependent promyelocytic leukemia protein turnover. J Biol Chem. 2011;286(52):44403-44411.

47. Jain P, Konoplev S, Benjamini O, Romagura J, Burger JA. Long-term control of refractory follicular lymphoma after treatment of secondary acute promyelocytic leukemia with arsenic trioxide (As2O3) and all-trans retinoic acid (ATRA). Blood Res. 2018;53(2):169-172.

48. Alsafadi S, Even C, Falet C, al. Retinoic acid receptor alpha amplifications and retinoic acid sensitivity in breast cancers. Clin Breast Cancer. 2013;13(5):401-408 